\title{
Frustration effect: The length of blocking interval and magnitude of incentive
}

\author{
JOHN L. ALLEN \\ Spring Arbor College, Spring Arbor, Michigan 49238
}

In a series of three experiments, forty Sprague-Dawley females were randomly assigned to groups which differed in incentive magnitude in the goalbox. The subjects were then trained for 10 days in a straight alley with no obstruction of approach to the goal. During testing, the rats received two nonblocked and four blocked (delay) trials per day for 11 days. Groups receiving four or nine 45-mg pellets on each trial ran significantly faster following delays than following no delay and tended to be faster following a 4 -sec delay than following longer delays. Delay had a similar effect on both running speeds and ingestion rates, with the 4- and 20 -sec delays producing a significant frustration effect for running and ingestion in the third experiment.

The frustration effect as originally reported by Amsel and Roussel (1952) was demonstrated with rats in a double alley apparatus consisting of a startbox (SB), first alley $\left(A_{1}\right)$, first goalbox $\left(G_{1}\right)$, second alley $\left(A_{2}\right)$, and second goalbox $\left(G_{2}\right)$. The frustration effect consisted of faster running in $A_{2}$ when the rat was not reinforced in $G_{1}$. Scull (1973) has recently summarized the results of much of the research involving frustrative nonreinforcement.

A manipulation to which Brown and Farber (1951) attributed frustration eliciting properties, namely, introduction of a delay between the initiation and completion of a response sequence, has received very little attention. This neglect is especially perplexing since frustration by delay appears to be confounded with nonreinforcement in the Amsel and Roussel study and in subsequent studies using their paradigm. In short, is Amsel's "frustration effect" due to removal of an anticipated reward in $G_{1}$, to delaying the approach to the reward in $G_{2}$, or to a combination of both factors?

The first study specifically designed to investigate the effects of varied intervals of delay in $G_{1}$ on $A_{2}$ running speeds of rats which were never reinforced in $G_{1}$ was conducted by Holder, Marx, Holder, and Collier (1957). Both the 15-sec and the 45-sec delay groups ran faster in $\mathrm{A}_{2}$ than the 1-sec delay group. Other investigators, on the other hand, have generally failed to find a frustration effect with a delay procedure (Ludvigson, 1968; Williams \& Ellis, 1970; Wist, 1962). However, Uyeno (1965), who criticized Wist for using a between groups design, found a frustration effect with a $1-\sec$ delay when using a within subjects but not when using a between groups design. It should be emphasized that

This study was based on a doctoral dissertation submitted to Michigan State University in partial fulfillment of the requirements for the PhD degree. The author would like to give special thanks to his dissertation director, M. Ray Denny, and to Mark Rilling. Stanley Ratner, and Lawrence $O$ 'Kelly for serving as committee members. Thanks also go to Mark Owen, Marcia Whiting, and Gloria Evert. Requests for reprints should be sent to John L. Allen, Spring Arbor College, Spring Arbor, Michigan 49283.

The author recognizes that Experiments II and III are not experiments in the usual sense of the term, but are follow-up groups suggested by the original experiment.
Williams and Ellis held their rats in the startbox for $5 \mathrm{sec}$ before the start of a trial.

Results of pilot work indicated that delaying rats in the startbox prior to the beginning of a trial tended to eliminate any frustration effect due to delay. In light of this finding, the present study was able to investigate the effect of length of blocking interval and magnitude of incentive on running speeds and ingestion rates by eliminating the delay in the startbox.

\section{EXPERIMENT I}

\section{Method}

Subjects. The subjects were 20 experimentally naive female Sprague-Dawley rats obtained from a local supplier. All subjects were approximately $\mathbf{9 0}$ days old at the start of the experiment, housed individually, and maintained with Allied Mills Mouse Breeder Blocks on a 22-h food deprivation schedule.

Apparatus. Except for the length of the alleys, the apparatus was similar to one used by Wagner (1959). The flat black startbox was $1 \mathrm{ft}(30.48 \mathrm{~cm})$ long, and like the remainder of the apparatus was 3 in. $(7.62 \mathrm{~cm})$ wide and 5.25 in. $(13.34 \mathrm{~cm})$ deep. Separating the startbox from Alley $1\left(A_{1}\right)$ was a guillotine type door painted black on both sides. All other doors in the apparatus were also guillotine. $A_{1}$ was $3 \mathrm{ft}(91.44 \mathrm{~cm})$ long, painted flat black, and had a floor covered with a black rubber mat. Separating Al from the delay box was a retrace door painted black on both sides. The delay box was identical to the startbox except that the guillotine door was painted white on the side facing the second alley $\left(A_{2}\right)$. $A_{2}$ contained two photoelectric cells - one placed $1 \mathrm{ft}(30.48 \mathrm{~cm})$ from the door leading into $A_{2}$ which started a timer and one placed $2 \mathrm{ft}(60.96 \mathrm{~cm})$ from the same door which stopped the timer. Both photoelectric cells were 1.5 in. $(3.81 \mathrm{~cm})$ above the floor and were connected to two Hunter Model 330 S photo contact relays. The relays were connected to each other and to a 1/100-sec Stoelting Model 22025-S clock by means of an Advanced Electric and Relay Co. Model PC 2C115VA relay. The openings in the alley were covered with thin sheets of red plastic. $A_{2}$ was $4 \mathrm{ft}$ $(121.92 \mathrm{~cm})$ long, painted white, and had a floor covered with .25 in. $(6.35 \mathrm{~mm})$ mesh hardware cloth. The door separating $A_{2}$ from the goalbox was painted white on both sides. The goalbox had the same dimensions as the delay box and was painted white with a white plastic foodcup mounted in the center of the end wall at floor level. The alleys were constructed of wood and were covered with clear Plexiglas; the startbox, delay box, and goalbox were covered with hinged sections of Plexiglas. 


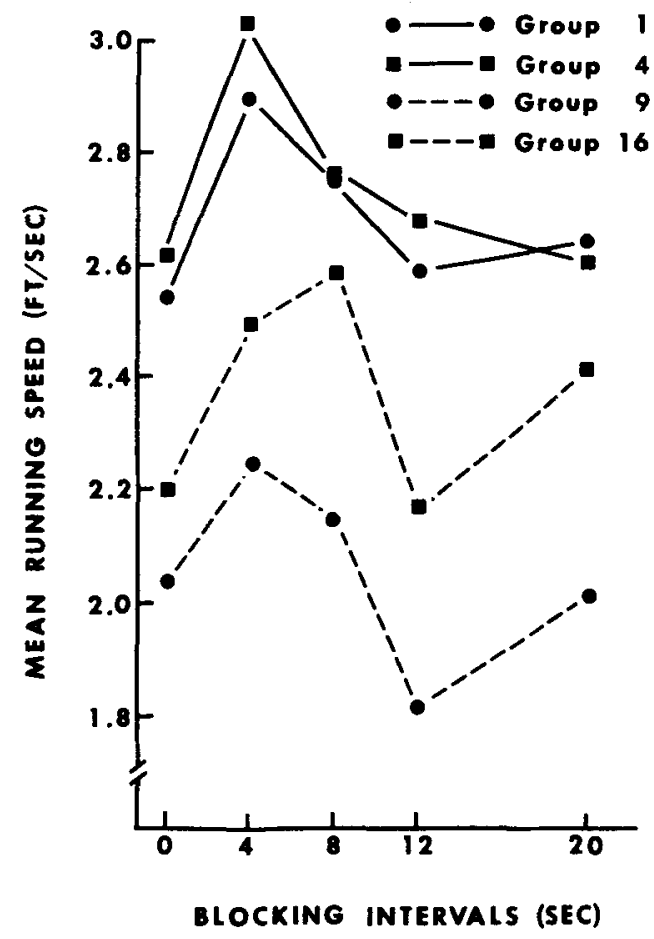

Figure 1. Mean running speeds at each blocking interval during Days 7-11 of Experiment I.

The runways, light sources, relays, and clock were placed on a table which was centered against one of the walls of the sound-deadened laboratory. Five gray holding boxes with water available were situated against the opposite wall of the laboratory.

Procedure. Habituation. Preliminary training lasted 10 days during which a 22-h food deprivation schedule was established. Water was available at all times in the home cage. For 3 days each rat was handled for a 5-min period before being fed for $1 \mathrm{~h}$ in an individual home cage; for the next 3 days each rat was placed in a holding box for $15 \mathrm{~min}$ before being fed; and for the last 4 days they explored the maze in groups of two for $5 \mathrm{~min}$ each day. During this period, the photocells and clock were operating to adapt the rats to these noises. After exploration, each rat was fed five 45-mg Noyes pellets from the floor of the holding box and then was returned to its home cage.

Training. The 20 subjects were randomly assigned to four equal-sized groups: a 1-pellet group (Group 1), a 4-pellet group (Group 4), a 9-pellet group (Group 9), and a 16-pellet group (Group 16). Each group was given the same number of pellets during training and testing. The order in which the groups were brought to the laboratory was randomized each day, as was the order in which the rats in each group were run. Each rat was given six 0 -sec delay training trials daily during the 10 days of training.

A 0 -sec delay trial was initiated with the introduction of the rat into the startbox. All doors from the startbox to the goalbox were left open, allowing the rat to traverse the entire length of the runway unobstructed. The first time on each trial that the rat passed through both photobeams while maintaining its goal orientation, the time was recorded as the running time for that trial. If a rat broke only the first beam and then retraced, the clock was reset. As soon as the rat entered the goalbox, the retrace door was closed and ingestion time was recorded. Ingestion time was measured by starting a stopwatch when the rat took the first pellet into its mouth and stopping it when it had taken the last pellet. Each rat was removed from the goalbox as soon as it had eaten. Ingestion time was not recorded for the 1-pellet group.

Testing. Each of the 11 testing days consisted of six trials: two 0 -sec delay trials and four trials on which each rat was held in the delay box for either $4,8,12$, or $20 \mathrm{sec}$. The opaque door into $A_{2}$ was not opened following the delay intervals until the rat was oriented toward it. The order in which the intervals were presented was randomized each day with the stipulation that the two 0-sec delay trials could not follow each other. Running times and ingestion times were measured and recorded as in the training trials.

The minimum intertrial interval throughout was $7 \mathrm{~min}$. After each group was run, the rats were placed in their home cages for $5 \mathrm{~min}$ and then fed for $1 \mathrm{~h}$.

\section{Results}

All running times were converted to running speeds $(\mathrm{ft} / \mathrm{sec})$, and all ingestion times were converted to ingestion rates (pellets/sec).

Training. Running speeds obtained from the last 5 days of training, after approach to the goalbox had stabilized, showed no significant differences between groups $[F(3 / 16)=.90, p>.05]$. However, a between groups comparison of ingestion rates did reveal significant differences $[F(2 / 12)=7.34, p<.01]$ with Group 4 displaying a significantly faster ingestion rate $(p<.05)$ than either Group 9 or Group 16.

Testing. A within groups analysis of variance for the second through the sixth days of testing revealed no significant differences between running speeds across delay intervals, as was expected. Since no blocking was involved in training, the rats tended to investigate the door blocking their entrance into $A_{2}$ and continued to investigate it after it was raised. This exploratory behavior postponed direct approach to the goalbox for several days, resulting in faster running speeds on the 0 -sec delay trials. Uyeno (1965) observed the same type of exploratory behavior when testing followed nonblocked training trials.

An analysis of the mean running speeds from the last 5 days of testing revealed similar patterns across delay intervals for the four incentive levels (see Figure 1). Although a within groups analysis for running speeds did not reveal a significant frustration effect (no delay on which running was significantly faster than on a 0 -sec delay), the 4-pellet group did approach significance $[F(4 / 16)=3.00$, critical $F$ for $p=.05$ is 3.01$]$, and a Newman-Keuls revealed that the difference between the 4- and 0-sec running speeds also approached the .05 level. That this occurred only for the 4-pellet group is in keeping with the suggestion by Deaux (1973) that ingestion speed is the best measure of incentive value. During both training and testing, Group 4 had the fastest ingestion rates.

In Groups 1 and 4 the fastest running was observed after the 4-sec delay interval. Although Group 9 also showed maximum running speed after the 4-sec delay, the slope between the 4-and 8-sec intervals is not nearly as steep as in the first two groups. Group 16 had its fastest running speed after the 8 -sec delay. These 
findings suggest a gradual shift in the optimal blocking interval from 4 to $8 \mathrm{sec}$ as the magnitude of the incentives increased. It is also interesting to note that mean running speeds for Groups 1,9 , and 16 tended to be faster following a $20-\mathrm{sec}$ delay than following a $12-\mathrm{sec}$ delay, which suggests the possibility of an even greater increase in running speeds for delays longer than $20 \mathrm{sec}$.

Group 9 yielded a significant difference in ingestion rates across delay intervals $[F(4 / 16)=7.21, p<.01]$ There was a weak but reliable frustration effect reflected in ingestion rather than in running, with both the 4- and $12-\mathrm{sec}$ delays producing significantly faster ingestion then the 0 -sec delay $(\mathrm{p}<.01)$.

A between groups analysis of running speeds for all groups was conducted, and no significant differences were found $[F(3 / 16)=1.50, p>.05]$. As in training, a significant difference was obtained between ingestion rates $[F(2 / 12)=24.97, p<.01]$. A Newman-Keuls analysis revealed that Group 4 had an ingestion rate significantly faster $(p<.01)$ than either Group 9 or 16 .

\section{EXPERIMENT II}

This experiment was prompted by the trend of an increase in running speed from the 12-sec to the $20-\mathrm{sec}$ blocking intervals in Experiment I. A 45-sec delay interval was substituted for the 20-sec interval in an effort to discover whether a longer delay would result in even faster running speeds. A 9-pellet incentive level was used to allow a comparison of mean running speeds obtained, with those of Holder et al. (1957) who used a .3-g incentive and 1-, 15-, and 45-sec delay intervals. The Holder et al. study used a between groups design and found that the 45-sec delay yielded the greatest effect; the present experiment used a within subjects design.

\section{Method}

Subjects and Apparatus. The subjects were 10 experimentally naive female Sprague-Dawley rats approximately 90 days old from the same source and maintained the same way as in Experiment I. The same apparatus was used.

Procedure. Habituation and training were identical to that used in Experiment $I$. Testing differed in that all subjects received nine 45-mg Noyes pellets in the goalbox, and a $45-\mathrm{sec}$ blocking interval was substituted for the 20 -sec interval.

\section{Results}

On the last 5 testing days, an analysis for repeated measures revealed a significant difference among running speeds for the various blocking intervals $[F(4 / 36)=5.33$ $\mathrm{p}<.01]$. A Newman-Keuls analysis showed that all four blocking intervals resulted in significantly faster running speeds than the 0-sec interval. The 4-, 8-, and 45-sec intervals were significantly faster at the .01 level and the $12-\mathrm{sec}$ at the .05 level. Although the frustration effect was observed for all blocking intervals, the 4-sec interval, as in Experiment I, seemed to produce the maximum running speed. These findings do not contradict those of Holder et al. (1957) in which they used 1-, 15-, and 45-sec delay intervals and observed a direct relationship between running speed and length of delay interval (a 1-sec training interval was used). The present experiment revealed a similar relationship between running speed and the 0-, 12-, and 45-sec delay intervals, even though Holder et al. used a between groups and the present study used a within subjects design (see Figure 2). However, the present results, given the inclusion of the 4-sec delay, suggest that the optimal blocking interval lies between 0 and $12 \mathrm{sec}$, an area not investigated in the Holder et al. study. A significant difference between ingestion rates across delay intervals was observed $[\mathrm{F}(4 / 36)=2.96, \mathrm{p}<.05]$; however, a Newman-Keuls analysis revealed no significant frustration effect.

\section{EXPERIMENT III}

This was essentially a replication of Group 4 in Experiment I (which approached a significant frustration effect); the primary difference was an increase in the number of subjects.

\section{Method}

Subjects and Apparatus. Ten naive rats from the same source and treated in the same manner as in Experiments I and II were used. The apparatus was identical to the one used previously.

Procedure. Habituation and training were conducted as in Experiment I. Testing was identical to that given Group 4 of Experiment I.

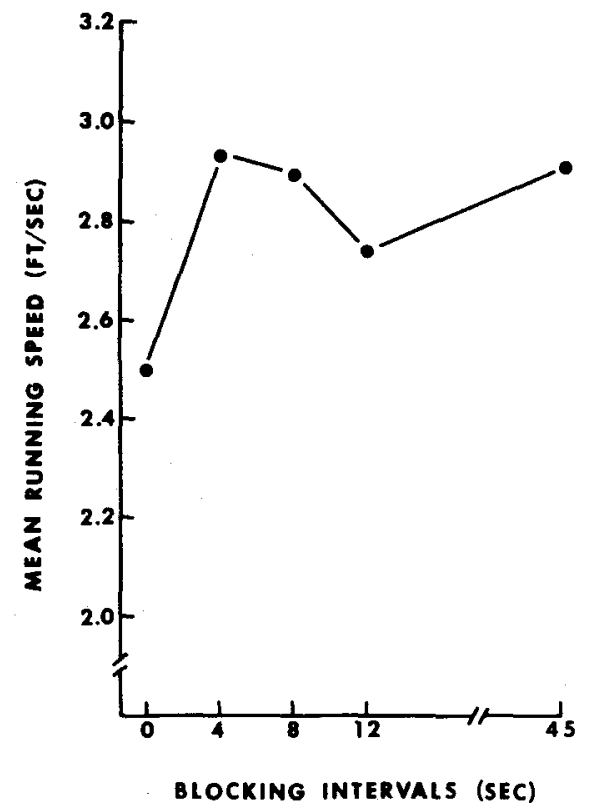

Figure 2. Mean running speeds at each blocking interval during Days 7-11 of Experiment II. 


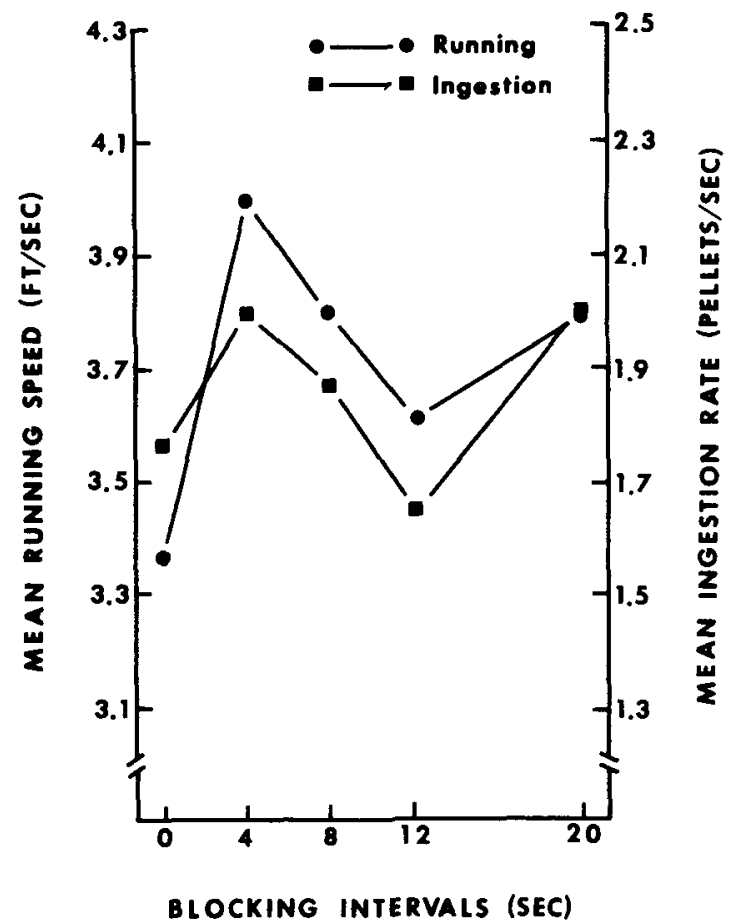

Figure 3. Mean running speeds and ingestion rates at each blocking interval during Days 7-11 of Experiment III.

\section{Results}

Running speeds across delay intervals differed significantly $[\mathrm{F}(4 / 36)=5.50, \mathrm{p}<.01]$. Three of the delay intervals, 4, 8, and $20 \mathrm{sec}$, with the 4-pellet incentive, resulted in significantly faster running speeds than the 0 -sec delay, with 4 significantly faster at the .01 level and 8 and 20 faster at the .05 level. The plot of mean running speeds across delay intervals (see Figure 3 ) is similar to that obtained for Group 4 in Experiment I. In both experiments the 4-sec delay interval is optimal, and the slope between the 4- and 8-sec delay intervals is steep when compared to subjects given a 9-pellet incentive. The only place where the curve of the 4-pellet group in Experiment I differs from the 4-pellet group of this experiment is between the 12- and 20-sec delay points, with the 4-pellet group in Experiment I showing a higher mean running speed on the 12-sec delay interval than on the 20-sec delay, exactly the opposite of what was observed in this experiment and in Groups 1, 9, and 16 of Experiment $I$.

A significant frustration effect was also found for ingestion rate $[F(4 / 36)=7.76, p<.01]$. Differences between intervals obtained by Newman-Keuls analysis revealed that the 4- and $20-\mathrm{sec}$ ingestion rates were significantly faster than the 0 -sec ingestion rates $(\mathrm{p}<.05)$ and significantly faster than the $12-\mathrm{sec}$ ingestion rates $(p<.01)$. The 8 -sec ingestion rates were also faster than the $12-\mathrm{sec}$ ingestion rates $(\mathrm{p}<.05)$. It is interesting to note that the plot of running speeds across delay intervals is quite similar to that obtained for ingestion rates (see Figure 3).

\section{DISCUSSION}

The data from the main experiment and the two follow-up experiments indicate that the frustration effect is obtainable with the blocking procedure used. Blocking studies which have failed to obtain a frustration effect have used different procedures. Wist (1962) and Williams and Ellis (1970) confined their subjects in the startbox at the beginning of each trial. Holding the subjects in the startbox at the beginning of each training trial may very well prevent an "expectation" (a well established nonblocked approach sequence) from developing (Denny \& Adelman, 1955). Ludvigson (1968) did not administer unobstructed trials together with blocked trials, thus failing to maintain an expectation for a clear path to the goal.

Of the various delay intervals used in this study, the 4-sec delay tended to produce the fastest mean running speed in all groups except in Group 16 of Experiment I. The 8-sec delay tended to produce the fastest mean running speed in the 16-pellet condition. The 4-sec delay appears to be long enough to energize responding and short enough to prevent competing responses in the delay box. Direct observation indicated that the rats were more tangentially active, turning and scratching, in the delay box with longer delays. Such activity during a blocking interval was followed by a slower approach to the goal. The subjects with the fastest approaches tended to maintain goal orientation with their noses at the bottom of the unopened $A_{2}$ door. As the delay intervals were increased to 20 or $45 \mathrm{sec}$, the mean running speeds again increased to a level approaching that obtained with the 4-sec delay, suggesting a possible increase in the effect of frustration so that effective competition in the delay box is reduced. It is important to note that competing responses (stopping, turning, investigating, etc.) were not observed in $\mathbf{A}_{2}$ during testing, with a direct approach to the goal being the rule.

The 4- and 9-pellet incentive levels both resulted in a significant frustration effect. Since 4 pellets resulted in a frustration effect for both running and ingestion in Experiment III, it seems to be at or near the optimal number for obtaining a reliable frustration effect. In other words, frustration effect does not seem to be a direct function of incentive magnitude either because ingestion rate is a better measure of incentive value than magnitude or because large incentive magnitudes during training result in the elicitation of more competing responses with their removal (Denny \& Ratner, 1970).

The 4-pellet incentive also resulted in the fastest mean ingestion rate. A direct correlation between speed of running and speed of eating is clearly suggested by the fact that mean ingestion rates plotted across delay intervals produce curves which are very similar to those obtained for running speed. Both the 4- and 20-sec delay intervals produced significant frustration effects for running and ingestion in Experiment III. 
The present study is different from the Amsel and Roussel (1952) study in that the present one involved only frustrative blocking while Amsel and Roussel's involved both frustrative blocking and frustrative nonreinforcement. Although this suggests the possibility that at least part of the frustration effect observed in the Amsel-Roussel study is due to blocking, the technique used in this study, namely, no holding in the startbox or anywhere else in the alley during training, leaves the matter in some doubt.

As previously indicated, most of the studies which have held subjects in the startbox on training trials, as was done in the Amsel-Roussel study, have failed to find a frustration effect when only blocking was used during testing, suggesting that frustrative nonreward by itself is strong enough to energize running in $A_{2}$. In any case, the present experiment has demonstrated in a way different from both Wagner (1959) and Tortora (1973) that demotivation (feeding in $A_{1}$ on nontest trials) can be eliminated as an alternative explanation of the frustration effect.

\section{REFERENCES}

Amsel, A., \& Roussel, J. Motivational properties of frustration I. Effect on a running response of the addition of frustration to the motivational complex. Journal of Experimental Psychology, 1952, 43, 363-368.
Brown, J. S., \& Farber, I. E. Emotions conceptualized as intervening variables - with suggestions toward a theory of frustration. Psychological Bulletin, 1951, 48, 465-485.

Deaux, E. Ingestion rate as a reward-magnitude variable in classical and instrumental conditioning in rats. Journal of Comparative and Physiological Psychology, 1973, 82, 308-315.

Denny, M. R., \& Adelman, H. M. Elicitation theory: I. An analysis of two typical learning situations. Psychological Review, 1955, 62, 290-296.

Denny, M. R., \& Ratner, S. C. Comparative psychology. Homewood, Ill.: The Dorsey Press, 1970.

Holder, W. B. Marx, M. H. Holder, E. E. \& Collier, G. Response strength as a function of delay of reward in a runway. Journal of Experimental Psychology, 1957, 53, 316-323.

Ludvigson, $H$. W. Interaction of midchain detention and reward magnitude in instrumental conditioning. Journal of Experimental Psychology, 1968, 78, 70-75.

Scull, J. W. The Amsel frustration effect: Interpretation and research. Psychological Bulletin, 1973, 79, 352-361.

Tortora, D. F. The effect of incentive size on response amplitude during acquisition and extinction. Unpublished doctoral dissertation, Michigan State University, 1973.

Uyeno, E. T. Effect of frustrative blocking on motivation. Psychological Reports, 1965, 16, 203-208.

Wagner, $A$. R. The role of reinforcement and nonreinforcement in an "apparent frustration effect." Journal of Experimental Psychology, 1959, 57, 130-136.

Williams, J. L., \& Ellis, J. D. The effects of delay on an established response. Psychological Record, 1970, 70, 251-258.

Wist, E. R. Amount, delay, and position of delay of reinforcement as parameters of runway performance. Journal of Experimental Psychology, 1962, 63, 160-166.

(Received for publication March 10, 1975. Revision received July 7,1975 .) 